\title{
Elementos para una caracterización marxista del neoliberalismo*
}

\author{
DANIEL ESPINOZA CARRASCO**
}

Artículo recibido: 30 de septiembre de 2017

Artículo aprobado: 3 de abril de 2018

Doi: http://dx.doi.org/10.12804/revistas.urosario.edu.co/desafios/a.6135

Para citar este artículo: Espinoza Carrasco, D. (2019). Elementos para una caracterización marxista del neoliberalismo. Desafios, 31(1), 157-192. Doi: http://dx.doi.org/10.12804/ revistas.urosario.edu.co/desafios/a.6135

\section{Resumen}

Según diversas caracterizaciones del neoliberalismo, este es una ideología económica que se materializa en un plan de gobierno cuyo objetivo es el libre mercado. El problema de dichas nociones radica en su ambigüedad y en pensar el neoliberalismo a partir de lo que este sostiene de si mismo. La tesis central de este articulo es que el neoliberalismo es un fenómeno eminentemente politico, lo que remite especificamente al Estado. Con los conceptos que aporta la teoría marxista de Poulantzas se da cuenta de una función y de las relaciones que el Estado sostiene con una formación social. Lo anterior permite interpretar los cambios sociales acontecidos a partir de la irrupción de gobiernos neoliberales y sus reformas, estableciendo una base sobre la que se describen las particularidades del Estado neoliberaly sus diferencias con otras formas de Estado. En este punto, la noción de acumulación por desposesión aporta elementos clave para entender cómo opera el neoliberalismo.

Palabras clave: neoliberalismo, Estado, marxismo.

\footnotetext{
* Agradezco al doctor Felipe Lagos por su revisión, comentarios y recomendaciones.

** Sociólogo, Universidad de Chile. Magíster en Políticas Públicas, Universidad de Chile. Investigador independiente. Correo electrónico: daniel.espinoza.carrasco@gmail.com. ORCID: https://orcid.org/0000-0002-3920-6036
} 


\title{
Elements for a Marxist Characterization of Neoliberalism
}

\begin{abstract}
Various characterizations of neoliberalism have described it as an economic ideology that materializes in a government program, whose objective is the free market. The problem of these notions lies in its ambiguity and in thinking about neoliberalism starting from what it claims for itself. The central thesis of this article is that neoliberalism is an eminently political phenomenon, which refers specifically to the state. Using concepts from Poulantzas' Marxist theory, it is possible to account for the function and relationships that the state maintains with a social formation. This allows us to interpret the social changes that have taken place since the irruption of neoliberal governments and their reforms, establishing a basis on which the particularities of the neoliberal state and its differences with other forms of state are described. At this point the notion of accumulation by dispossession provides key elements to understand how neoliberalism operates.
\end{abstract}

Keywords: Neoliberalism, state, marxism.

\section{Elementos para uma caracterização marxista do neoliberalismo}

\begin{abstract}
Resumo
Diversas caracterizações do neoliberalismo o têm descrito como uma ideologia econômica que se materializa em um plano de governo cujo objetivo é o livre mercado. O problema destas noções radica em sua ambiguidade e em pensar o neoliberalismo a partir do que se este sustenta de si mesmo. A tese central deste artigo é que o neoliberalismo é um fenômeno eminentemente político, o que remite especificamente ao Estado. Com os conceitos que aporta a teoria marxista de Poulantzas, dá-se conta de uma função e de relações que o Estado sustenta com uma formação social. O anterior permite interpretar as mudanças sociais acontecidas a partir da irrupção de governos neoliberais e suas reformas, estabelecendo uma base sobre a que se descrevem as particularidades do Estado neoliberal e suas diferenças com outras formas de Estado. Neste ponto a
\end{abstract}


noção de acumulação por despossessão aporta elementos chave para entender como opera o neoliberalismo.

Palavras-chave: neoliberalismo, Estado, marxismo.

\section{Introducción}

Las movilizaciones estudiantiles del año 2011 en Chile lograron cambiar los contenidos de la agenda pública al cuestionar políticas que por muchos años no fueron parte del debate. Esto permitió develar un malestar generalizado en la población, al punto que incluso se llegó a hablar del "derrumbe del modelo" (Mayol, 2012). La particularidad, ese año - aparte de las protestas masivas-, fue que los estudiantes no se quedaron simplemente en la demanda gremial de más financiamiento o de mejoras a la calidad de la educación, sino que realizaron un análisis y una crítica más profundos que apuntaban a todo el sistema económico y político nacional: el neoliberalismo.

De esta manera, los debates sobre el modelo de desarrollo se han tomado la agenda política, con especial énfasis en la relación entre el Estado y ciertos derechos sociales (como educación, salud o previsión) hoy privatizados. De ahí que la demanda sea por un Estado que vuelva a garantizar el acceso a dichos bienes en vez de funcionar como mero subsidiario. A esto se suma un contexto regional marcado por proyectos políticos que han buscado levantarse como una alternativa al neoliberalismo ${ }^{1}$.

En este punto se hace necesario realizar una caracterización profunda de lo que entenderemos por neoliberalismo. La importancia de esta discusión se da en varios planos. Por una parte, el término no tiene un uso unívoco: encontramos diferencias radicales entre posturas liberales que lo niegan, posturas progresistas y unas marxistas. Por otra, el debate político se aclara al tener nociones más rigurosas acerca de qué es un modelo de desarrollo o de cuáles son las características particulares del actual. Esta es la única manera de abrirse paso a través

\footnotetext{
1 Para una revisión de algunos de estos gobiernos ver Buendía García, Mateo \& Medialdea (2013).
} 
de los eslóganes fáciles y de políticas públicas que, lejos de terminar con el neoliberalismo, solo apuntan a su consolidación.

En ese sentido, considero que las definiciones del neoliberalismo que se encuentran en la literatura no son del todo satisfactorias, en tanto no logran capturar su especificidad y cómo opera en realidad. El presente artículo busca aportar elementos para una caracterización a partir de la teoría marxista de las formaciones sociales. La tesis central es que este es un fenómeno eminentemente político, por lo que remite al Estado específicamente. No es que "las complejidades de los procesos y la vida social la obligarán [a la ideología neoliberal] a recurrir a lo mismo que niega, la política, para imponerse" (Garretón, 2013, p. 23), sino que ella misma, originariamente, recurre a la política, en particular a su elemento distintivo: el Estado. Esto tiene consecuencias en la delimitación del campo donde ubicaremos aquello que buscamos analizar, tanto conceptual como políticamente.

Sin embargo, circunscribir el neoliberalismo al Estado presupone ciertas nociones sobre este y cómo se relaciona con el resto de una formación social. Es necesario entender que, si bien el Estado forma parte de lo que Marx denominó superestructura, esto no lo reduce a ser un mero apéndice o reflejo de la base económica. Por el contrario, los distintos niveles de una formación social ejercen determinaciones múltiples y recíprocas, lo que implica, evidentemente, una articulación orgánica compleja entre los distintos componentes. Esto explicaría por qué el neoliberalismo, siendo algo político, termina por manifestarse en las estructuras productivas de los países donde se implementa. En este sentido, siguiendo a Nicos Poulantzas, el Estado tiene la función fundamental de cohesionar los distintos niveles de esa unidad compleja. Esta conceptualización es la que permite explicar de manera más satisfactoria el éxito de la revolución neoliberal acontecida en Chile a partir de 1973.

\section{El concepto en contexto}

La discusión sobre el concepto de neoliberalismo es amplia, tanto entre disciplinas de las ciencias sociales como en las corrientes teóricas y 
políticas que lo abordan. Se intentará aquí hacer una breve revisión de autores que aporten a este debate sin la pretensión de una revisión bibliográfica exhaustiva ${ }^{2}$, sino más bien con la de encontrar una idea, al menos general, de lo que se entiende por neoliberalismo en este.

Diversos autores han señalado que su origen se encontraría en la fundación de la Mont Pelerin Society, en 1947, bajo el alero del filósofo y economista austríaco Friedrich von Hayek (Garretón, 2013, p. 24; Harvey, 2015, p. 26) donde, además, participaron Ludwig von Mises, Walter Lippman, Michael Polanyi y Milton Friedman, entre varios otros. Otra hipótesis sostiene que el origen del pensamiento neoliberal está en el texto Camino de servidumbre, de Hayek, que data de 1944, aunque estaría evidentemente ligado a la Mont Pelerin Society (Anderson, 2003, p. 11). Algunos autores van más allá al señalar que el concepto neoliberal fue acuñado en 1938 durante un coloquio convocado por Lippman y al que habrían asistido prácticamente las mismas personas ya mencionadas (Dávalos, 2008, p. 7; Ghersi, 2004, pp. 297-298; Laval \& Dardot, 2013, p. 67). En cualquier caso, como se dijo, más allá de diferencias respecto a fechas, tanto el momento histórico como los pensadores asociados al origen del neoliberalismo parecen ser materia en la que existe amplio acuerdo.

Ahora bien, en este punto surge la primera dificultad ya que ninguno de estos pensadores — ni tampoco sus herederos — se han definido a sí mismos como "neoliberales", sino que se siguen declarando simplemente liberales. Por el contrario, el término "neoliberal", según ellos mismos, es más bien usado por sus detractores: los "enemigos de la libertad" (Ghersi, 2004, pp. 308-311). Lo anterior, por tanto, plantea la pregunta de qué sería el neoliberalismo y qué constituye su especificidad.

\footnotetext{
2 Tarea que excede los objetivos de este trabajo. Solo por citar un trabajo reciente y ambicioso, se recomienda a Springer, Birch y MacLeavy (2016), quienes compilan cincuenta y siete artículos que tratan los orígenes del neoliberalismo, sus implicancias políticas y las tensiones sociales, geográficas y ambientales que conlleva.
} 
Se podría afirmar, en términos generales, que el neoliberalismo es "aquella visión y práctica sobre la sociedad dominada por el mercado como principio ordenador de toda la vida social" (Garretón, 2013, p. 9). Las definiciones disponibles, en general, apuntan a dos aspectos: primero una ideología — en un sentido laxo del término, como visión, conjunto de ideas, etc.- luego, un cierto programa de gobierno para poner en práctica dichas ideas. Christian Laval y Pierre Dardot detectan bien esta dualidad al señalar que "el neoliberalismo ha sido interpretado, por lo general, como si fuera al mismo tiempo una ideología y una política económica directamente inspirada en esta ideología” (2013, p. 12).

En este sentido, para David Harvey, el neoliberalismo "es, ante todo, una teoría de prácticas político-económicas que afirma que la mejor manera de promover el bienestar del ser humano consiste en no restringir el libre desarrollo de las capacidades y de las libertades empresariales del individuo dentro de un marco institucional caracterizado por derechos de propiedad privada fuertes, mercados libres y libertad de comercio" (Harvey, 2015, p. 6). De forma similar, Perry Anderson (2003) entiende que el neoliberalismo es un "programa" de gobierno cuyas ideas centrales fueron planteadas por los fundadores de la Mont Pelerin Society. Sin embargo, su oportunidad de irrupción se dio solo a fines de la década de los setenta mediante gobiernos que destacaron por contraer la emisión monetaria, el recorte de gastos fiscales, la baja en los impuestos, las privatizaciones masivas y una fuerte legislación antisindical. También Pierre Bourdieu habla de un programa teórico que, transformado en un programa político, tiende a hacer real una cierta utopía planteada por dicha teoría: la de un mercado puro y perfecto logrado con reducción del costo de mano de obra, recortes en el gasto público y un mercado laboral flexible (Bourdieu, 1998, p. 95). Así, el neoliberalismo tendría como principales características el libre mercado, la reducción del gasto público, la privatización y la desregulación económica (Vargas Hernández, 2011, p. 80).

La idea común de las definiciones mencionadas es que este es una serie de medidas, ideas, políticas cuyo ámbito de acción es la economía, lo que lo lleva a conceptualizarlo como un fenómeno principal - pero no exclusivamente- económico. Lo que ocultan es una 
definición clara de neoliberalismo donde, bajo el paraguas de "teoría" o "programa", se entremezclan nociones como política, economía e ideología ${ }^{3}$. Pero más allá de esta ambigüedad, lo claro pareciera ser la esencia del neoliberalismo, a saber, la de una economía de mercado sin trabas de ningún tipo, que sobrepasa los desarrollos geográficos desiguales y las diversas aplicaciones, parciales y sesgadas, que se han dado en las distintas formaciones sociales (Harvey, 2015, p. 20). Por esto mismo es que, para poder explicar las tensiones entre lo que el neoliberalismo dice de sí mismo y hace en realidad (Harvey, 2015, p. 28), ha terminado por entenderse como una utopía (Bourdieu, 1998; Garretón, 2013, p. 23; Harvey, 2015, p. 24), conceptualización que le permite responder a críticas que sostienen que bajo la etiqueta de neoliberal se engloban gobiernos muy disímiles (Ghersi, 2004, p. 307), ya que, en realidad, no existiría ninguna sociedad verdaderamente neoliberal (Garretón, 2013, p. 23) sino gobiernos que, en mayor o menor medida, se acercan a dicha utopía de un mercado perfecto y totalmente desregulado.

Como respuesta a esta perspectiva, surge un enfoque basado en el concepto de "gubernamentalidad", acuñado por Michel Foucault, que apunta a rebasar la idea de que el neoliberalismo es una mera ideología y una política económica al sostener que es una racionalidad, una serie de discursos, prácticas y dispositivos que determinan una forma específica de gobierno y de establecer relaciones sociales, basada en la competencia (Garretón, 2013; Laval \& Dardot, 2013, p. 15). Esta noción supera varias de las limitaciones que conlleva entender el neoliberalismo como una ideología en tanto la racionalidad neoliberal es más que la mera aplicación de una teoría e implica filtros inconscientes (Laval \& Dardot, 2013, pp. 24-25), aproximándose así a nociones más elaboradas de la ideología y de la hegemonía. Es, en definitiva, una definición más profunda del neoliberalismo que permite pensar más allá de la idea, quizá demasiado simple, de una política económica que se intenta llevar a la práctica. Esta conceptualización podría entenderse como lo que Žižek llama "saberes desconocidos";

\footnotetext{
3 Por ejemplo, para Dávalos (2008, p. 2), el neoliberalismo es económico, político, ético, histórico, jurídico y simbólico.
} 
cosas que sabemos, pero que no sabemos que sabemos y que estructuran nuestro sistema social y político (Featherstone, 2007, p. 111). Así, pues, se deja el foco de una política económica y se pasa al ámbito del gobierno, no en sentido estricto sino en tanto capacidad de dominación y de los mecanismos a través de los cuales esta opera.

Por otra parte, este enfoque permitiría, según los autores, establecer de manera más precisa la especificidad del neoliberalismo en relación con el liberalismo, evitando caer en la idea de que el primero es un mero retorno a este último (Laval \& Dardot, 2013, p. 23) ${ }^{4}$. A juicio de ellos, la diferencia principal radicaría en una fuerte crítica realizada al antiguo liberalismo por su fe dogmática en un "orden natural" (Laval \& Dardot, 2013, p. 76). Sin embargo, aquella idea no resulta del todo convincente al leer textos de pensadores considerados neoliberales, donde se aprecia un rechazo fuerte al Estado y a la política, al tiempo que se realiza una apología del mercado como un orden mucho más perfecto que el que jamás podría lograrse desde una instancia centralizada, como el Estado (Hayek, 1982). Tampoco se entiende mucho la diferencia con el liberalismo si el principio articulador de la gubernamentalidad —entendida como discursos, prácticas y dispositivos - neoliberal es la libre competencia.

De esta forma no queda muy clara la distinción liberalismo/neoliberalismo en el planteamiento realizado por Laval y Dardot. Por otra parte, el foco en la racionalidad, o en la asimilación de una racionalidad determinada por parte de los gobernados, difumina un poco los instrumentos a través de los cuales dicha dominación se logra. Esto último tiende a invisibilizar los marcos materiales que condicionan determinadas pautas de dominación y de su asimilación (o no) por parte de los dominados, pese a que la idea de gubernamentalidad sugiere superar las nociones meramente ideológicas apuntando a aspectos como prácticas y dispositivos sociales ${ }^{5}$.

\footnotetext{
4 Por ejemplo, para Featherstone (2007, p. 116), el neoliberalismo es, prácticamente, un retorno al estado de naturaleza.

5 Eagleton (1991, pp. 7-8) critica la noción de poder de Foucault —la misma detrás de la idea de una gubernamentalidad - al señalar que, al situarlo en todas partes, lo vacía de significado (esto
} 
Se ha revisado una serie de definiciones y nociones de lo que sería el neoliberalismo, o qué es aquello que lo caracterizaría, donde hay diferencias considerables entre distintas nociones que, sin embargo, parecen concordar con respecto a los rasgos fundamentales. No obstante, lo que se intentará plantear a continuación es que, más allá de los factores relevantes del neoliberalismo, hay también una ambigüedad extendida en la bibliografía revisada, en particular sobre sus límites. Primero, se lo suele considerar como una "ideología” económica sin establecer claramente sus alcances y restricciones. Luego, la idea de una racionalidad neoliberal, si bien apunta a superar la primera visión, a partir de la introducción de discursos, prácticas y dispositivos, no logra escapar de la ambigüedad presente en la primera definición, así como tampoco da con aquello que constituye su especificidad en relación con el liberalismo.

Lo que se argumentará a continuación, a partir de un marco teórico marxista, es que el neoliberalismo es principalmente político — contra lo que los mismos neoliberales puedan pensar de sí mismos-, lo que remite, necesariamente, a una caracterización del Estado. Solo a partir de este es posible pensar en nuevas formas de racionalidad, de gobierno y de dominación.

\section{Aspectos conceptuales}

Este argumento trabajará con base en tres ejes fundamentales: i) la distinción que hace la teoría marxista entre base y superestructura; ii) la idea de la sociedad como un todo complejo; y iii) el papel fundamental que cumple el Estado en una formación social.

en referencia al concepto de ideología que está ligado al de poder). La solución que encontraría Foucault es abandonarlo por el de "discurso", pero aquí se pierde la posibilidad de jerarquizar conflictos con base en su impacto en la estructura social. En definitiva, lo que Eagleton le cuestiona a Foucault — cuestionamiento extensible a la noción de gubernamentalidad - es precisamente que un concepto político central se diluya en una infinidad de elementos: racionalidad, prácticas, dispositivos estatales, no estatales, etc. 


\section{Base y superestructura}

Los conceptos de base y superestructura ${ }^{6}$ forman una de las ideas más discutidas de Marx. Y es que la ausencia de un desarrollo profundo de dichas tesis ha dado pie a toda clase de interpretaciones. Así, por una parte, esta tesis se ha interpretado como un determinismo economicista absoluto, donde la superestructura es un mero "reflejo" o "fenómeno" de la base económica ${ }^{7}$. El polo, contrario a esta concepción, radica en la exaltación de la autonomía intrínseca de estas instancias que existen con una naturaleza previa y entran en relación dentro de un modo de producción (Poulantzas, 2005, p. 10). Ambas nociones, pese a sus conclusiones aparentemente opuestas, parten de la misma premisa: separación radical entre base y superestructura.

Por otra parte, ha habido una tendencia, como respuesta a las dos primeras interpretaciones, a negar la tesis de la distinción base/superestructura ${ }^{8}$ argumentando que dicha posición instala una separación que no existe como tal y niega así la posibilidad de entender la sociedad como una totalidad orgánica.

Ambas posiciones constituyen extremos errados que se alejan de la noción que esta pareja de conceptos busca instalar aunque, antes de entrar a precisar esto, resulta importante adelantar cuál es el sentido y la validez de esta tesis. Marx sostiene que para la producción de la vida, los hombres contraen determinadas relaciones de producción

6 Aunque en la edición que se utilizará el concepto ha sido traducido como "edificio" (Marx, 2013, pp. 347-348), se empleará el término "superestructura" porque se ha usado con mayor frecuencia.

7 Aquí destacan las interpretaciones que llenaron los numerosos manuales soviéticos durante el siglo xx. Por ejemplo: "Sabiendo, como lo demuestra la teoría materialista, que las ideas son el reflejo de las cosas, que es nuestro ser social el que determina la conciencia, diremos, pues, que la superestructura es el reflejo de la infraestructura" (Politzer, 1961, p. 58).

8 Por ejemplo: "En este caso — ya lo hemos recordado— Lenin utiliza el término de esqueleto: la formación económico-social es el esqueleto en torno al cual se articula toda la sociedad. A partir de esta visión el marxismo ya no es una teoría dedicada a analizar la vida económica sino la totalidad de la vida social. Además [...] Lenin se colocaba fuera de la concepción del materialismo histórico que había caracterizado las posiciones anteriores y que planteaba la cuestión en términos de relación infraestructura/superestructura" (Aricó, 2012, p. 146). 
-independientes de su voluntad - que corresponden a una fase determinada del desarrollo de las fuerzas productivas. Y a continuación afirma lo siguiente:

La totalidad de esas relaciones de producción constituye la estructura económica de la sociedad, la base real sobre la cual se alza un edificio [Uberbau] jurídico y político, y a la cual corresponden determinadas formas de conciencia social. El modo de producción de la vida material determina [bedingen] el proceso social, político e intelectual de la vida en general (Marx, 2013, pp. 4-5).

¿Qué se debe entender por esta “determinación económica”? Marx tuvo que hacer frente a las mismas objeciones que, hasta el día de hoy, se le imputan a su teoría, a las cuales respondió argumentando que la determinación económica se refiere a que el surgimiento de distintas instituciones, a lo largo de la historia, es posible gracias a las formas en que las distintas sociedades han producido sus medios de existencia ${ }^{9}$. De esta manera, la determinación de la que habla Marx son las condiciones de posibilidad materiales de una sociedad específica dadas por su base económica, por su capacidad y por su forma de producir. Esto queda aún más claro cuando Engels dice que Marx descubrió:

[...] el hecho, tan sencillo, pero oculto bajo la maleza ideológica, de que el hombre necesita, en primer lugar, comer, beber, tener un techo y vestirse antes de poder hacer política, ciencia, arte, religión, etc.; que, por tanto, la producción de los medios de vida inmediatos, materiales, y por consiguiente, la correspondiente fase económica de desarrollo de un pueblo o una época es la base a partir de la cual se han desarrollado las instituciones políticas, las concepciones jurídicas, las ideas artísticas e incluso las ideas religiosas de los hombres y con arreglo a la cual deben, por tanto, explicarse, y no al revés (Engels, 1980, p. 91).

\footnotetext{
9 "Es indudable que ni la Edad Media pudo vivir del catolicismo ni el mundo antiguo de la política. Lejos de ello, lo que explica por qué en una era fundamental la política y en la otra el catolicismo es precisamente en el modo como una y otra se ganaban la vida" (Marx, 2006, p. 46).
} 
Teniendo en consideración estas aclaraciones, cuesta pensar todavía que la superestructura sea objeto de una determinación mecánica de la base económica donde, para cada régimen de producción, existe un solo tipo de sistema jurídico-político que le "corresponde". Lo que hace la estructura económica de la sociedad es sentar una base sobre la que es posible la emergencia de un determinado tipo de instituciones, creencias, etc. No por ser capitalistas tendremos un solo tipo de Estado sino, más bien, los Estados que conocemos solo son una realidad posible en tanto existan relaciones capitalistas de producción.

Por lo tanto, defender la tesis de la distinción base/superestructura es defender el materialismo del marxismo. No se trata de negar la noción de totalidad; se trata de entender que las cosas no existen por sí solas, sino que necesitan de una base material que las posibilite, en este caso, las relaciones de producción (la economía).

\section{Un todo complejo}

Lo explicado anteriormente es la premisa básica del materialismo histórico. A partir de ella se puede problematizar la relación entre la base económica y la superestructura jurídica.

La teoría general del materialismo histórico define un tipo de relaciones entre instancias distintas y unidas (Poulantzas, 1972, pp. 7-8) de una formación social. El principio de distinción y el principio de unidad entre la base económica y la superestructura pueden llevar, por lo menos, a dos equívocos. El primero consiste en radicalizar dicha distinción, mientras que el segundo error es hacer primar el principio de unidad, anulando las distinciones entre los elementos, perdiendo la capacidad de distinguir a qué obedece cada fenómeno, algo contra lo cual previno Marx ${ }^{10}$ y que tiene consecuencias en la propia práctica

\footnotetext{
10 “... siempre es menester distinguir entre el trastocamiento material de las condiciones económicas de producción [...] y las formas jurídicas, políticas, religiosas, artísticas o filosóficas, en suma, ideológicas, de las de las cuales los hombres cobran conciencia de este conflicto y lo dirimen" (Marx, 2013, p. 5).
} 
política $^{11}$. Es por ello que se hace necesario defender ambas ideas: la distinción entre la base y la superestructura, al mismo tiempo que la relación de unión entre ambas. Lo que está en juego es la noción de unidad, de totalidad.

Aquí se hacen necesarios los aportes de Althusser quien, a partir de una crítica a la noción hegeliana de totalidad, problematizó la noción marxista de esta al argumentar cuáles serían sus características específicas y las que la distinguirían de cualquier concepción anterior. Al basarse en las premisas del líder y teórico chino Mao Tse-Tung, su razonamiento parte de la base de que nada se desarrolla de manera absolutamente igual de tal manera que, en una formación social, existen múltiples y diferentes contradicciones, lo que solo es posible en una unidad compleja y estructurada (Althusser, 2004, p. 166). Esta premisa permite concebir contradicciones principales y contradicciones secundarias, al tiempo que da pie para plantear la posibilidad de que estos papeles varíen en momentos determinados, pasando a ser primaria la contradicción que antes fue secundaria y viceversa (Althusser, 2004, p. 175). Esta situación de desplazamiento del dominio principal de las estructuras explicaría, tal como señalaba Marx aludiendo a la Antigüedad y a la Edad Media, que una época sea dominada por la política y otra por la religión y no necesariamente siempre por la base económica ${ }^{12}$.

Y he aquí la necesidad de definir qué se entenderá por totalidad marxista. Este requerimiento conduce, de manera inevitable, a la comparación que hace Althusser entre la concepción hegeliana y la marxista, la cual a pesar de su apariencia abstracta, tiene implicancias políticas bastante concretas.

\footnotetext{
11 "La abolición de la especificidad misma de lo político, su desmenuzamiento en todo elemento indistinto (...) tienen por resultado hacer superfluo el estudio teórico de las estructuras de lo político y de la práctica política, lo que conduce a la invariante ideológica voluntarismo-economismo, y a las diversas formas de revisionismo, reformismo, espontaneísmo, etc." (Poulantzas, 1972, p. 35).

12 De todas formas, es la base económica, el modo en que cada sociedad se "ganaba la vida", lo que "explica" por qué dichas estructuras eran las fundamentales en esas épocas. De esto se tratan los conceptos de "determinación en última instancia" y "autonomía relativa" (Althusser, 2004, p. 91).
} 
La unidad en Hegel es simple, no hay diferenciación interna pues todas las diferencias no son sino un único principio interno "enajenado". La diferencia entre Hegel y Marx no es, sencillamente, que el primero sea idealista y el otro materialista, como si una cosa fuera lo contrario de la otra, sino que dicen algo completamente distinto, siendo la principal diferencia que, en Hegel, no hay distinción interna, por lo que no puede haber determinaciones de ningún tipo. "Para Hegel el principio que unifica y determina la totalidad social no es tal 'esfera' de la sociedad sino un principio que no tiene ningún lugar ni cuerpo privilegiado en la sociedad, por la razón siguiente: que reside en todo lugar y en todo cuerpo" (Althusser, 2004, p. 169). Por el contrario, la contradicción en el marxismo sería siempre sobredeterminada, concepto acuñado por Althusser para describir una multiplicidad de contradicciones independientes las unas de las otras, originadas en los distintos niveles de la formación social (Althusser, 2004, p. 174).

Si se sacrifica la distinción interna en nombre de la totalidad, se caería en una concepción hegeliana de esta con las siguientes consecuencias: i) la base económica y la superestructura son lo mismo, expresiones de un único principio simple; ii) no puede existir un desarrollo desigual de las diversas instancias; iii) no puede existir sino una contradicción; iv) no puede haber desplazamientos en las contradicciones; por lo que, v) al ser siempre la misma contradicción principal no hay especificidades dentro de un modo de producción; en consecuencia, vi) la práctica política queda reducida a una mínima expresión, a la única contradicción que articula la sociedad capitalista: la contradicción capital-trabajo.

Los aportes de Althusser permiten comprender que la unidad marxista es aquella que articula orgánicamente la complejidad en una totalidad. Plantear que la unidad esté internamente diferenciada no atenta contra la noción de totalidad ya que no se trata de sacrificar la unidad en nombre del pluralismo, sino de afirmar que la totalidad del marxismo es la unidad de la complejidad (Althusser, 2004, p. 167). La multiplicidad de contradicciones orgánicamente estructuradas es lo que constituye la unidad. 
Así, al afirmar que existe una base económica y una superestructura jurídico-política, que es realmente distinta, no se niega que haya una totalidad sino que esta sea simple, que los distintos componentes de una sociedad sean parte de un mismo elemento originario y, por lo tanto, siempre reductibles a él. Negar la complejidad de una estructura social, el desarrollo desigual de sus elementos y la multiplicidad de contradicciones y las variaciones de sus funciones, es adoptar una noción demasiado vaga de totalidad que arroja poca información sobre los procesos históricos reales. La tesis de que para el marxismo la unidad es siempre compleja dando paso a una serie de determinaciones cruzadas, múltiples y desiguales — la sobredeterminaciónpermite despejar tanto los fantasmas del mecanicismo economicista, como los del idealismo de la unidad abstracta. La sociedad es una unidad compleja, compuesta por distintos elementos orgánicamente vinculados, pero diferentes los unos de los otros, irreductibles los unos a los otros.

Entender las formaciones sociales como totalidades complejas estructuradas permite entender la existencia de, no una, sino de múltiples contradicciones en el interior de esta. Permite a su vez entender el desarrollo desigual de las contradicciones de un proceso. Según Althusser, estas características constituyen la especificidad de la contradicción marxista y resultan fundamentales para un entendimiento profundo del neoliberalismo.

\section{Función del Estado}

Tenemos, entonces, dos instancias principales: base y superestructura, distintas pero orgánicamente unidas y sobredeterminadas. Lo que faltaría es aquello que mantendría la unidad de una formación social, lo que conduce al trabajo de Poulantzas sobre el poder político y el Estado ${ }^{13}$.

Según este autor, la función del Estado va mucho más allá del gobierno o de simplemente ostentar el monopolio de la violencia física. No

\footnotetext{
13 Esto no agota, en ningún caso, el debate sobre el Estado en el marxismo; sin embargo, no constituye el objetivo del presente texto.
} 
se trata solo de administrar el poder en el sentido despectivo que le daba Marx en el Manifiesto; de lo contrario, ningún esfuerzo político revolucionario tendría por objetivo el poder del Estado. Y no se debe pensar solo en la Rusia de 1917, sino también en el Chile de 1973, es decir que también la ofensiva neoliberal apuntó directamente a hacerse del Estado.

El Estado es un factor de cohesión social; lo que el marxismo ha concebido como un factor de "orden" o principio de organización, no en el sentido común de "orden político" simplemente, sino "en el sentido de la cohesión del conjunto de los niveles de una unidad compleja, y como factor de regulación de su equilibrio global, en cuanto sistema" (Poulantzas, 1972, pp. 43-44). De esta manera, el Estado es el lugar que articula los distintos niveles de una formación social y que vela por el mantenimiento de dicha articulación, es decir, por mantener las condiciones de la producción. Por ello, el Estado establece relaciones específicas con cada uno de los niveles de la sociedad a través de modalidades que adopta en su función global de orden político: modalidad técnico-económica en el nivel económico; modalidad propiamente política en el nivel de la lucha política de clases; y modalidad ideológica en el nivel ideológico (Poulantzas, 1972, p. 52). En este sentido, el Estado no tiene, propiamente hablando, una función técnico-económica, sino una modalidad técnico-económica de la función política de cohesión social que es la función que le corresponde específicamente (Poulantzas, 1972, p. 52).

Así, el Estado opera como el gran regulador, el gran principio de orden que asegura la conservación de las condiciones de la producción y, por lo mismo, las condiciones de existencia y de funcionamiento de una formación social específica (Poulantzas, 1972, p. 51). En este sentido, el Estado tiene la capacidad de ejercer determinaciones en otros niveles de la sociedad — como el económico - sin reducirse a un mero reflejo de la base económica, para lo cual cuenta con mucho más que las herramientas propias de su aparato represivo — que son las más destacadas por los clásicos del marxismo_-; además posee toda una red de aparatos ideológicos (Althusser, 2008, pp. 18-29). 
Ahora bien, la función de orden se da en un contexto de sociedad de clases pues el Estado surge cuando esta se ha enredado en una contradicción irreconciliable consigo misma, a fin de evitar que dichos intereses antagónicos en pugna se devoren y la consuman (Lenin, 1960, p. 298). Es decir, el Estado tiene por misión evitar que dichas contradicciones se desarrollen al punto de destrucción de la sociedad. La función de orden es, por tanto, una función de clase.

Así, en el marco de una sociedad de clases atravesada por contradicciones, el Estado entra en relación con las contradicciones propias de cada uno de los niveles de una formación social y, al ser el lugar en que se refleja la articulación de dichos niveles, termina por ser la confesión de "la contradicción de la sociedad consigo misma", para así llegar a la siguiente conceptualización: el Estado es "el resumen oficial" de la sociedad (Poulantzas, 1972, p. 49). De esta forma, en tanto articulador de los diversos niveles de una formación social, el Estado enlaza sus contradicciones y es, por tanto, el lugar donde todas esas se condensan (Poulantzas, 1972, p. 44), por lo que de ahí puede extraerse el conocimiento de la unidad para descifrar su situación de ruptura (Poulantzas, 1972, p. 50). En otras palabras, al ser el Estado el factor de orden de la formación social es al mismo tiempo el elemento que permitiría su ruptura.

Para finalizar, estas son las características del Estado que definen su lugar en la práctica política, cuyo objetivo específico, para Poulantzas (1972, p. 50), son las estructuras políticas que constituyen el poder institucionalizado del Estado. De esta forma, la práctica política tiene por objeto el "momento actual", produce su transformación —o su conservación - (Althusser, 2004, p. 144), pero solo en la medida en que tiene por objetivo estratégico específico las estructuras políticas del Estado (Poulantzas, 1972, p. 41). Esto por la función que desempeña el Estado en el seno de una formación social y que permite, por tanto, la modificación o conservación de ese "momento actual". 


\section{Neoliberalismo}

\section{Consideraciones previas}

Para comenzar, es necesario explicar por qué las definiciones revisadas en el segundo aparte no resultarían satisfactorias desde una perspectiva marxista. Como se planteó, todas las nociones vistas, incluida la de Harvey, de una u otra forma plantean que el neoliberalismo es un tipo de ideología, en un sentido laxo, ya sea como un conjunto de ideas, una visión, una mentalidad o una racionalidad. Se trata siempre de ideas llevadas a la práctica, de formas de "ver" la sociedad que determinan ciertas formas de actuar, ciertas prácticas o dispositivos que apuntan a cumplir un ideal — que sería la libre competencia - a partir del cual se articulan una racionalidad determinada, una institucionalidad política, una dominación, una cohesión y un orden social específico.

Ahora bien, la idea del neoliberalismo como una ideología de la libre competencia tiene dos problemas principales. El primero es que si se le entiende como un conjunto de ideas, se remite a eso, a las ideas, y no a su existencia real. La consecuencia más evidente es que se termina por aceptar lo que el neoliberalismo dice de sí mismo, lo que es inaceptable desde una perspectiva materialista ${ }^{14}$ ya que no explica la diferencia entre el discurso neoliberal y su aplicación concreta ${ }^{15}$. Pero este problema tiene otra derivada que se relaciona con cómo proponemos entender el neoliberalismo, ya que si aceptamos que es un conjunto de ideas relacionadas con la libre competencia, aceptamos que es todo aquello que predica: más mercado, menos Estado. Ese principio se apoya en una premisa tan fundamental como falsa: la dicotomía entre Estado y mercado. Al analizar cualquier proceso de

\footnotetext{
14 "Así como no se juzga a un individuo de acuerdo a lo que este cree ser, tampoco es posible juzgar una época semejante de revolución a partir de su propia conciencia, sino que, por el contrario, se debe explicar esta conciencia a partir de las contradicciones de la vida material, a partir del conflicto existente entre las fuerzas sociales productivas y relaciones de producción” (Marx, 2013, p. 5).

15 Es algo similar a lo que ocurre con el capitalismo y los monopolios. Marx sostuvo que la competencia capitalista tiende inevitablemente a los monopolios, algo muy contrario al discurso de libre competencia que predica el capitalismo.
} 
instauración neoliberal, es fácil llegar a la conclusión de que la primacía del mercado no se da porque este le gane una suerte de competencia al Estado sino porque, desde el Estado mismo, se le dan más atribuciones al mercado. En ese sentido, y tal como señala Karl Polanyi (2015, pp. 105-117), el mercado existe gracias al Estado.

El segundo problema tiene relación con los límites de las definiciones y, por lo tanto, con lo que es y lo que no es el neoliberalismo. Al hacer una analogía, el capitalismo es entendido por Marx como un modo de producción, esto es, una determinada forma de organizarla a través de relaciones sociales a partir de las cuales se levanta la superestructura jurídica, política e ideológica. Considerando esto, resulta evidente que el capitalismo tiene una ideología que le es propia y cuyo objetivo debe ser naturalizar la existencia de la propiedad privada de los medios de producción y legitimar, tanto a dominados como a dominadores, dicho orden social. Pero eso no puede conducir a la confusión de pensar que el capitalismo es una ideología porque ello nos aleja de un análisis materialista con la consecuencia, advertida por Marx, de no distinguir entre las transformaciones materiales y las ideológicas, lo que conduce peligrosamente al abandono de la crítica al modo de producción capitalista, renunciando a plantear la necesidad de abolir la propiedad privada de los medios de producción.

De la misma forma, no resulta conveniente pensar el neoliberalismo como una ideología porque lo que propone es pensarlo como algo omnipresente, sin límites y, por lo tanto, sin un lugar o nivel específico al qué apuntar en caso que se quisiera eliminarlo. Cuando un concepto lo es todo, finalmente pierde su capacidad explicativa y, cuando se trata de uno vinculado en particular con política y disputas de poder, se termina por perder la noción de jerarquías en la disputa política en el sentido de cuáles de ellas son las centrales para un orden social determinado (Eagleton, 1991, pp. 7-8).

Un ejemplo de este problema se puede ver en la definición planteada por Laval y Dardot quienes mueven las coordenadas fijadas por Marx para entender el capitalismo — la base económica - para así fusionar capitalismo y neoliberalismo. Cuando los autores plantean 
que el neoliberalismo es la razón del capitalismo contemporáneo, entendiéndolo como el "conjunto de los discursos, de las prácticas, de los dispositivos que determinan un nuevo modo de gobierno de los hombres según el principio universal de la competencia" (Laval \& Dardot, 2013, p. 15), dan a entender que el capitalismo es una cierta manera de gobierno cuya forma actual sería la neoliberal. De nuevo, siguiendo a Marx, el capitalismo es un modo de producción, un tipo de relaciones sociales de producción sobre las cuales se levanta una superestructura jurídica y política, por lo que es evidente que el capitalismo implica determinados tipos de gobierno. Pero esto no es lo mismo que reducir el capitalismo a discursos y prácticas propias de un modo de gobierno (un modo de dominación); aquello es transformar completamente la noción marxista del capitalismo.

Lo que está verdaderamente en juego aquí es la agenda política, porque si el problema es tan solo un determinado tipo de gobierno, bastaría con cambiarlo, con una nueva racionalidad y con una serie de prácticas que regulen la libre competencia. Pero, entonces, ¿dónde queda el problema de la propiedad de los medios de producción? Así, la realidad económica del capitalismo — que es su esencia— deja de ser problematizada. Esta identidad neoliberalismo/capitalismo opera como una barrera que frena el acceso analítico y político a los niveles de las fuerzas productivas y de las relaciones sociales de producción, llevando todo el problema a la dominación y las formas que toma. Por eso este esfuerzo de clarificación conceptual se orientó a enfatizar en la distinción entre base y superestructura como una necesidad analítica pero también política; como una necesidad de fijar líneas de demarcación entre un programa de transformación y otro.

Todo esto nos pone frente a dos posibilidades: englobar todos los cambios sociales ocurridos a partir de la década de los setenta bajo el término de neoliberalismo o distinguir entre un cambio en la base económica y un cambio en la superestructura, concediéndole a uno de ellos el término de neoliberalismo. Con la primera opción se corre el riesgo de diluir la especificidad de cada uno de los cambios y de cometer el error del cual Marx nos previene en el "Prólogo". 
Con esto se busca apuntar a lo siguiente: la necesidad de examinar el desarrollo de las fuerzas productivas y la adaptación que han experimentado las relaciones sociales de producción capitalista en las últimas décadas. En dicho análisis radica la única posibilidad de una crítica verdaderamente anticapitalista, que cuestione la existencia de la propiedad privada de los medios de producción al reivindicar el rol fundamental que posee la clase trabajadora como aquella que crea valor. Por lo pronto, surge la necesidad de restringir el concepto de neoliberalismo, dejando claros sus límites, para no perder de vista lo que debe ser el elemento central de un análisis marxista y no pensar que la problematización del neoliberalismo sustituye la problematización de las relaciones sociales de producción, de la base económica de nuestro modo de producción que se fundamenta en la existencia de la propiedad privada de los medios de producción.

En este sentido, lo novedoso de nuestro "momento actual", aquello que distinguiría esta época, no se ubicaría en la base económica por el simple hecho de que las relaciones sociales de producción siguen siendo capitalistas. Ha habido cambios, en especial en el desarrollo de las fuerzas productivas, pero el capitalismo no ha sido superado y, por lo mismo, el neoliberalismo, si busca dar cuenta de la especificidad de nuestra época, no puede ser ubicado en las relaciones sociales de producción, es decir, no puede ser asimilado con el capitalismo.

No obstante, no se debe menospreciar la capacidad transformadora del neoliberalismo. Aun al delimitarlo y circunscribirlo al ámbito de la superestructura, la intención de repasar el concepto de sobredeterminación tenía como objetivo comprender las formas en que se relacionan las estructuras políticas, ideológicas y económicas. En ese sentido, y al revisar la historia del neoliberalismo y de cómo ha logrado hacerse del poder político no resulta posible negarle su capacidad de determinar lo que sucede en las otras estructuras sociales, precisamente porque ha logrado hacerse del Estado y, a partir de ahí, generar profundos cambios en los distintos niveles de la sociedad. Es por ello que el neoliberalismo merece un análisis particular y específico ya que si se concibe una unidad social sobredeterminada, no es políticamente 
factible detenerse solo en la base material, aunque sea un requisito sine qua non para una crítica verdaderamente anticapitalista.

Este artículo intenta contribuir a esto, razón por la que se sostiene que el concepto de neoliberalización no puede englobar todos los cambios surgidos a partir de los años setenta. La teoría marxista exige distinguir entre los cambios económicos y los cambios jurídicos, políticos, etc. A su vez, el neoliberalismo habla de una realidad política que no puede ser obviada, evadida ni tampoco absorbida en nombre del análisis de la base económica o en nombre de la preservación de la globalidad. Políticamente esto es insostenible.

\section{El neoliberalismo como proyecto político}

Hecho el rodeo es posible entrar de lleno en el objetivo de este texto.

El neoliberalismo debe ser entendido como un tipo particular de Estado, construido como respuesta a la crisis de acumulación sufrida por la clase capitalista durante la década de los setenta ${ }^{16}$. Esto permite arrojar las primeras luces sobre lo que es el Estado neoliberal: un proyecto político de la fracción financiera del capital. El neoliberalismo es, por tanto, y tal como señala Harvey, un proyecto de restauración del poder político de clase.

La idea de entenderlo como un Estado tiene la doble función de, por una parte, delimitar el concepto y por esa misma vía también el rango de acción y la magnitud de propuestas antineoliberales; pero al mismo tiempo le otorga una función central en una formación social, lo que le permite articularse con otras estructuras sociales que han sido vinculadas al concepto en otras definiciones. Dicho de otro modo, si se entiende el neoliberalismo como un Estado - en los marcos que señala Poulantzas-, tiene pleno sentido concebirlo como una forma de dominación política, al tiempo que tiene una vinculación específica

\footnotetext{
16 Esta definición está en línea con la de Therborn (2003, p. 19) para quien el neoliberalismo "es una superestructura ideológica y política que acompaña una transformación histórica del capitalismo moderno."
} 
con la ideología y con la economía al articular dichas conexiones para formar una unidad compleja y sobredeterminada.

Lo primero, entonces, sería recalcar la idea de que el neoliberalismo es un proyecto político, entendiendo que la especificidad de la práctica política radica en su objetivo estratégico: el Estado (Poulantzas, 1972, p. 41). Así, dado el contexto de baja en la tasa de acumulación, para la burguesía era imperativa una intervención política (Harvey, 2015, pp. 18-26) que lograra hacerse del Estado. Aquí es necesario ser enfático en el papel central que este cumple como cohesionador de una formación social contra planteamientos que ponen en duda su importancia frente al poder creciente de capitales transnacionales, por ejemplo ${ }^{17}$. El Estado es la instancia central de cohesión, articulación y regulación de las estructuras de una formación. Esta idea no solo resulta teóricamente más satisfactoria, sino más fácil de aceptar a la luz de los acontecimientos históricos donde la mayor o menor influencia de los capitales internacionales en los países solo ha sido posible a partir de una legislación que desregule mercados.

Volviendo al punto, el neoliberalismo es un proyecto político de la facción financiera del capital para restablecer las condiciones para la acumulación de capital y restaurar el poder de las élites (Harvey, 2015, p. 24). En tanto proyecto político que se encarna en determinado tipo de Estado, obedece a intereses materiales concretos, no a ideales abstractos. Se sabe que los intereses construyen ideas y valores a partir de los cuales se legitiman, pero no hay que olvidar que detrás de ellos hay grupos sociales que se benefician y otros que se ven perjudicados. Por lo mismo, la adopción de las ideas neoliberales se hace siempre y cuando estas sean una herramienta que beneficie a la clase que las esgrime. Corresponde a una interpretación en último término idealista pensar que las ideas son defendidas porque sí por parte de un grupo social, sin tomar en cuenta la función que cumplen y a quién le pueden servir. Por eso concebir el neoliberalismo como un conjunto de ideas se queda corto ya que la evidencia muestra que cuando

\footnotetext{
17 Cabe destacar la crítica que realiza Atilio Boron (2004) a las tesis de Antonio Negri y
} Michael Hardt que sostienen la pérdida de importancia política de los Estados y gobiernos. 
sus principios chocan con la necesidad de restaurar o de sostener el poder de la elite, estos son abandonados o tergiversados (Harvey, 2015, p. 26). En este sentido, Harvey es muy asertivo al señalar que el giro neoliberal no estuvo dado por la adopción del monetarismo, sino por el despliegue de políticas gubernamentales en muchas áreas además de la económica (Harvey, 2015, p. 31).

Definir el neoliberalismo como un proyecto político de clase que se encarna en un determinado Estado, en vez de un conjunto de ideas, permite entender por qué el Estado estadounidense, en vez de dejar operar el orden espontáneo del libre mercado, gastó más de doce billones de dólares tratando de detener la caída del sistema financiero tras la quiebra de Lehman Brothers, lo que tuvo como resultado la ampliación del poder y del patrimonio de los grandes bancos (Fazio, 2014, p. 137) ${ }^{18}$. Estas medidas solo tienen pleno sentido si las entendemos como parte de la modalidad técnico-económica de la función de Estado: a través de una función económica se cumple la función global de cohesión y orden social. Es evidente, entonces, que las ideas neoliberales quedan supeditadas a los intereses de la clase dominante para la que el libre mercado se defiende mientras sirva al orden social existente.

En Chile también existen ejemplos en los que la ortodoxia del "dogma", de la idea en su forma "pura", se contrapuso a los intereses de las clases dominantes. La crisis económica de comienzos de la década de los ochenta no encontró, por parte del gobierno, respuesta en la ortodoxia monetarista, lo que lo obligó a tomar el control de la mayor parte del sistema financiero a comienzos de 1983 (Gárate, 2012, p. 290). Así, la historia muestra que el neoliberalismo no es un recetario teórico sino un conjunto de medidas políticas para el beneficio del sector financiero de la burguesía. Esto significa que lo que en la teoría puede ser antineoliberal, en la práctica es una medida en beneficio de las clases dominantes.

18 Existen numerosos otros ejemplos (Harvey, 2015, p. 82). 
En este sentido es posible entender el neoliberalismo como un "modelo de desarrollo", pero siendo muy cuidadosos con el término. Si se considera un Estado al servicio de determinados sectores de la economía, a favor de determinadas facciones de la burguesía, es posible decir que el neoliberalismo ha tendido a fomentar los sectores primarios y terciarios de la economía. Pero esto no puede llevar a la conclusión de que el neoliberalismo es un modelo de desarrollo primario exportador por dos motivos. Primero, porque no habría diferencias con los antiguos Estados liberales o los modelos de desarrollo previos al sistema ISI (Industrialización por Sustitución de Importaciones). Segundo, porque existen Estados "posneoliberales", como los gobiernos bolivarianos de Venezuela y Bolivia que, sin ser neoliberales, tienen modelos de desarrollo primario exportador. Por lo tanto, la idea de "modelo de desarrollo", sin ser incorrecta, está supeditada al carácter de clase del Estado en cuestión.

Esto no se debe perder de vista porque, precisamente, la idea de un modelo de desarrollo da cuenta de una intencionalidad y de una dirección en las políticas públicas, en los impuestos y en leyes laborales. A partir del marco jurídico se benefician ciertos sectores sociales en detrimento de otros, en particular, de la clase trabajadora. Es decir, las actuales características de la economía — cuáles son sus sectores preponderantes - no se deben a un desarrollo específico de las fuerzas productivas en dichas áreas, sino a politicas de Estado. Por eso se sostiene la naturaleza primordialmente política del neoliberalismo sin que esto implique un aislamiento y una incapacidad para determinar lo que sucede en otras estructuras sociales; más bien, cualquier examen del neoliberalismo apunta a determinadas políticas económicas destinadas a producir determinados bienes, a fijar determinadas regulaciones, a establecer determinados objetivos. La constante es que, aunque se apunte a cambios económicos, todas estas medidas remiten al Estado. Por el puro hecho de hablar de políticas económicas o de políticas monetarias se hace referencia al Estado y, por lo tanto, en realidad se le asigna un papel al Estado, una función que debe desempeñar.

Así, el análisis histórico muestra que el neoliberalismo, más que una ideología, es un proyecto político concreto que, evidentemente, 
propone y esgrime ideas, pero defiende una estrategia de dominación de una clase específica. Este se materializa en un determinado tipo de Estado cuyas instituciones, políticas públicas y marco jurídico propician determinadas maneras de operar en la formación social a través de formas específicas de vinculación con los distintos sectores sociales que buscan asegurar la cohesión de la unidad social. Lo anterior da una estructura específica al Estado neoliberal que es necesario analizar.

\section{Estado neoliberal}

El desafío de caracterizar el Estado neoliberal comienza por diferenciarlo de uno propiamente liberal y por ir allende sus características aparentemente más obvias. Por ejemplo, en apariencia, el Estado neoliberal es débil y pequeño porque se retira de ciertos aspectos de la vida para dejárselos al mercado; pero lo que en realidad ha ocurrido son reconfiguraciones de las instituciones y de las prácticas estatales (Harvey, 2015, p. 88).

Es necesario comenzar por sus características más evidentes. Es posible describir el Estado neoliberal a partir del Consenso de Washington, un listado de políticas que los principales organismos financieros internacionales, en conjunto con instituciones políticas de Estados Unidos, redactaron a modo de recomendaciones para los Estados latinoamericanos en 1989. Si bien esto no constituye un hito fundacional, sí es una buena recopilación o síntesis de las principales características de un Estado neoliberal. Son diez medidas que tienden a dos objetivos generales: desregular los mercados y disminuir el gasto fiscal. Lo primero se logra con bajos aranceles, pocas restricciones legales a la instalación de empresas y a la instalación de capitales extranjeros, bajos impuestos y legislaciones laborales que mermen el poder de los sindicatos y trabajadores. El segundo objetivo es posible mediante la privatización de empresas públicas y el recorte y focalización del gasto a través, principalmente, de subsidios.

Junto a estas dos características encontramos una ofensiva contra toda forma de solidaridad social, en particular la sindical, por lo que se generan legislaciones que tienden a disciplinar, cuando no destruir, a los sindicatos (Harvey, 2004, p. 84). No hay que olvidar que la función 
del Estado afecta, en primer lugar, al nivel económico de la sociedad y, en particular, al proceso de trabajo (Poulantzas, 1972, pp. 54-55). En ese sentido, hay que mencionar también la modalidad propiamente política del Estado, la que interviene en el nivel de la lucha política de clases. Esta modalidad emplea los recursos en los que, con mayor detalle, repararon los clásicos del marxismo: el aparato (represivo) de Estado, compuesto por el gobierno, la administración, el Ejército, la Policía, los tribunales, las cárceles, etc. (Althusser, 2008, p. 24).

Las características recién mencionadas hablan de un tipo específico de la modalidad económica que adopta la función del Estado neoliberal. En otras palabras, se trata de comprender a través de qué mecanismos - modalidades que adopta para relacionarse con los diversos niveles de la formación social— el Estado neoliberal se propone el dominio de clase — su función global de orden político- - Es vital comprender que las acciones de todo Estado de clase apuntan en esa dirección. Así, si bien el Estado de bienestar significó una mejora en las condiciones de vida de la clase obrera, no se puede pensar como disociado de un proyecto determinado de dominación (Poulantzas, 1972, pp. 52-53). En ese caso, el Estado de bienestar recogió la advertencia que hiciera Marx en El capital: nada le conviene más a la burguesía que eliminar cualquier traba legal que se oponga al progreso del proletariado (Marx, 2006, p. xv).

Ahora bien, si en un algún momento el Estado cambió las modalidades de sus funciones, pasando del Estado liberal con predominio de la modalidad política -Estado "gendarme" (Poulantzas, 1972, p. 58) - a uno cuya modalidad predominante era la técnico-económica, se debió a la función global del Estado: mantener el orden social. En otras palabras, la producción se aseguraba de mejor manera con un Estado que interviniera la economía al asegurar las condiciones de existencia a la clase obrera. Dicho modelo de Estado toca techo en la década de los setenta y se hace necesaria una remodelación de este para que pudiera seguir cumpliendo su función al asumir nuevas modalidades. En este sentido, la especificidad del Estado neoliberal radica en la forma en que logra el objetivo de la cohesión social. Esta manera difiere del Estado liberal y del Estado de Bienestar. 
El Estado neoliberal toma elementos de ambos modelos de Estado anteriores, con lo que se despeja de antemano que sea un sencillo retorno al liberalismo. Esto es relevante porque empieza a develar la especificidad del Estado neoliberal y qué lo diferencia del Estado liberal. Precisamente, la modalidad predominante de su función política global sería, al igual que en el Estado de Bienestar, la técnico-económica. Esto parece contraintuitivo en tanto el neoliberalismo suele asociarse con un imperio del mercado. Pero desregulación de los mercados financieros no implica que el Estado deje de intervenir las economías. No solo en el sentido de una "no-intervención específica" (Poulantzas, 1972, p. 58), sino que a partir de intervenciones particulares de creación de mercados y transferencias monetarias que, en definitiva, son las que configuran y dan forma a la economía, supuestamente, librecambista. Son tres las operaciones clave a través de las cuales el Estado neoliberal genera los marcos con los que funcionan los mercados "libremente" y que se dan en el nivel económico de una formación social.

La primera es propiciar lo que Harvey ha denominado "acumulación por desposesión”. El autor señala que las condiciones reales del capitalismo le han obligado a recurrir continua y persistentemente a las prácticas depredadoras de lo que Marx denominó "la asíllamada acumulación originaria" y que, en tal caso, tal dinámica no puede remitirse a una situación primitiva u original, por lo que acuña el concepto de acumulación por desposesión (Harvey, 2004, p. 116). En términos concretos, son todas las políticas de privatización (Harvey, 2004, pp. 124-127) que han emprendido los estados neoliberales. Por ejemplo, las sucesivas oleadas de privatizaciones efectuadas por la dictadura chilena pueden ser entendidas como situaciones de acumulación primitiva o "por desposesión”, en tanto se libera un conjunto de activos a un coste muy bajo (Harvey, 2004, p. 119), lo que permite la creación de nuevos grandes grupos económicos ${ }^{19}$.

\footnotetext{
19 Tales oleadas privatizadoras y las crisis económicas que les siguieron reordenaron varias veces el "mapa de la riqueza" en Chile durante las décadas de los setenta y los ochenta, tal como lo estudió Fernando Dahse (1983, pp. 65-87).
} 
Sin embargo, podrían hacerse dos salvedades a la definición que Harvey ofrece. Primero, la idea de una acumulación originaria, más que a determinadas prácticas, se refiere a la configuración de una estructura de clases a partir de mecanismos coercitivos (privatización de tierras, etc.). En ese sentido, la privatización de tierras o empresas no genera, necesariamente, una situación de la así llamada acumulación originaria en tanto no propicia modificaciones sustanciales en la estructura de clases.

Segundo, la novedad de los procesos de privatización neoliberales está en la creación de mercados a partir de lo que antes se consideraban derechos sociales. Así, se observa una serie de mercados que, incluso durante el Estado liberal, no existían, tales como el de la educación, el de la salud, el de las pensiones. El caso más llamativo, quizás, es el de las Asociaciones de Fondos de Pensiones (AFP) en Chile, las cuales han permitido usar un ahorro forzado de los trabajadores como inyecciones de capital en los mercados financieros. Por ello sería preferible referirse a la acumulación por desposesión como aquella generada a partir de la mercantilización de derechos sociales. A eso habría que sumarle, además, la privatización — todavía vigente- de políticas públicas, esto es, la externalización que hace el Estado de determinados servicios que presta ${ }^{20}$, lo que se relaciona, además, con la tercera operación.

La segunda operación es la del Estado subsidiario. A partir de la privatización de servicios sociales y políticas públicas, el Estado ya no procura una red de seguridad social. Ya no es un Estado de derechos sino que subsidia a quienes quedan excluidos de los distintos mercados que entregan bienes (educación, trabajo, salud, etc.). La justificación está en la necesidad de reducir el gasto público. En virtud de lo anterior, se establecen criterios para priorizar el gasto, focalizándolo hacia los segmentos más empobrecidos a través de bonos. Ahora, si bien el Estado ya no participa en el mercado como proveedor, todavía lo hace a través de flujos monetarios a la población.

20 En Chile existe el caso de los hogares del Servicio Nacional de Menores (SEnAme): políticas definidas estatalmente pero ejecutadas por privados (Arredondo, 2015, p. 6). 
Esta operación específica, si bien es parte de la función económica del Estado, está sobredeterminada por la función política específica —no global — y apunta a un objetivo concreto: despolitizar las relaciones sociales. Ya se revisó qué se conserva del Estado de Bienestar: el predominio de la función económica. Ahora bien, la forma en que este predominio se lleva a cabo lo acerca más a la forma liberal de Estado en el sentido de que cuando este asumió tareas respecto del mercado, la dominación de clases no pudo seguir bajo la forma anónima de la ley de valor ya que los conflictos fueron "absorbidos" por el Estado con la consecuente repolitización de las relaciones de clase (Habermas, 1999, pp. 121-122). Precisamente, el giro que toma la intervención técnico-económica del Estado le permite resituar los conflictos en el nivel económico y queda la imagen —ilusoria - de un Estado mínimo, irrelevante, cuando en realidad es un escenario generado y mantenido por la acción estatal.

La tercera operación fundamental viene a cerrar al círculo y tiene que ver con que el Estado, aparte de subsidiario, es subsidiador del capital. Es la profundización de la privatización ya que el Estado no solo genera nuevos mercados para el capital, sino que subsidia a la clase burguesa mediante transferencias directas de dinero o garantías monetarias de ganancias.

En el caso chileno, la educación es un claro ejemplo de estos principios. En primer lugar se generó todo un mercado de la educación escolar y superior donde la mayor cantidad de establecimientos son privados y hay que pagarlos. Con la privatización de la educación, el capital puede acumular a partir de lo que debiera ser un derecho social (acumulación por desposesión). El Estado entrega becas para personas que acrediten su imposibilidad de pagar los costos de educación (subsidiariedad). Junto a lo anterior, a través de distintos mecanismos, el Estado entrega grandes cantidades de dinero a capitalistas (desde los dueños de colegios hasta bancos que entregan créditos) ${ }^{21}$.

\footnotetext{
21 Un estudio reciente concluyó que la cantidad de dinero que actualmente invierte el Estado chileno en educación superior permitiría financiar educación pública gratuita (Fundación Nodo XXI, 2015).
} 
Este giro en el funcionamiento del Estado no sería posible sin su reestructuración profunda. En efecto, la posibilidad de un Estado neoliberal está dada por un proceso de modernización específica de carácter tecnocrática al introducir una racionalidad técnica orientada a resultados y, supuestamente, neutra en términos políticos (Arredondo, 2015, pp. 3-7). Dicha modernización ha tenido consecuencias no solo en la función estatal, sino también en su estructura misma y en las relaciones que establece con sus propios trabajadores, al mermar sus derechos laborales e incorporar todo aquello que el empresariado ha empujado en el mundo privado: desregulación, flexibilidad laboral y abuso de formas contractuales que buscan negar derechos colectivos (Varas Marchant, 2016). El objetivo central de esta modernización va en la misma dirección que las operaciones mencionadas: la despolitización de las relaciones sociales.

Siendo así, desde el Estado se impulsa la reducción de la disputa política a su mínima expresión en todos los campos sociales posibles. Los sistemas políticos quedan ocupados por fuerzas políticas que no tienen proyectos políticos antagónicos, la administración estatal y las políticas públicas también se despolitizan, pasando a la hegemonía tecnocrática: no hay disputas políticas, solo proyectos más o menos eficientes.

Para cerrar, una última observación. Poulantzas señala que el predominio del papel técnico-económico del Estado indica que la preeminencia en la articulación de la formación social se encuentra en el nivel político (Poulantzas, 1972, p. 58). Por el contrario, cuando el predominio es del papel propiamente político, el nivel predominante en la sociedad es el económico. De esta manera, al postular que la modalidad preponderante de la función del Estado neoliberal es la técnico-económica, se postula la primacía del nivel político en la sociedad. Esto implica un rasgo de especificidad en tanto constituye una diferencia concreta respecto al Estado liberal. De ahí que el predominio de la modalidad técnico-económica esté sobredeterminada por la función política que actualmente apunta a despolitizar las relaciones sociales. Este objetivo se ampara en un fundamento que permea las distintas funciones, estructuras y prácticas del Estado: la idea de que no existen proyectos políticos alternativos. 
La caída del bloque socialista logró instalar la idea de que no hay orden social posible distinto al conocido (democracia liberal y economía de mercado). De ahí en adelante, lo que hemos vivido ha sido la consolidación, en palabras de Laval y Dardot, de una racionalidad, una serie de discursos, prácticas y dispositivos que determinan una forma específica de gobierno y de establecer relaciones sociales basadas en esa idea. Este principio sería el eje articulador de lo que se podría llamar gubernamentalidad neoliberal. Si bien no es uno de los rasgos originarios del Estado neoliberal, ya que estos surgieron cuando aún existía el campo socialista, es la coronación de un proyecto político que claramente apuntaba en la dirección de derrotar al socialismo como opción política.

Como se mencionó, el neoliberalismo es un proyecto de clase - de la clase burguesa- que surge en el contexto de una fuerte disputa contra los proyectos socialistas y socialdemócratas. Es por ello que la idea del fin de la historia debe considerarse como un triunfo del proyecto político neoliberal y, por tal motivo, asociado a él. En este sentido el triunfo neoliberal, con la consecuente hegemonía de la burguesía financiera, indican el lugar y la función particulares de lo ideológico en su relación con lo político o, en otras palabras, el funcionamiento político particular de la ideología burguesa (Poulantzas, 1972, p. 247), en este caso, de la ideología del fin de la historia: establecer los márgenes de la práctica política.

\section{Conclusiones}

El neoliberalismo constituye un proyecto político de la burguesía financiera como respuesta a las bajas en las tasas de ganancia en la década de los setenta. Esto, a diferencia de las posturas que lo identifican con una ideología, permite analizarlo con base en lo que hace y no en lo que dice. La especificidad de la práctica política radica en su objetivo estratégico que es el Estado, ya que este cumple la función de mantener la cohesión de los distintos niveles de una formación social a partir de relaciones específicas y sobredeterminadas con cada uno de esos niveles. 
Por eso el proyecto político de la burguesía financiera se encarna en un modelo particular de Estado: el neoliberal, que conserva la primacía de la modalidad técnico-económica de su función global, no solo por su sus recurrentes intervenciones económicas para correr en auxilio del gran capital, sino por otras operaciones generales y cotidianas: i) al crear nuevos mercados a partir de derechos sociales para generar una “acumulación por desposesión", lo que implica reemplazar su red de seguridad social por ii) bonos y subsidios solo a los segmentos de la población que se encuentran totalmente marginados del mercado, y donde, además iii) el capital recibe transferencias y garantías monetarias por parte del Estado en determinados rubros, generando una reorientación productiva del sector primario y de servicios.

Como cierre, es necesario extraer algunas conclusiones y plantear ciertos retos. Primero, ser antineoliberal alude directamente al conflicto de clases, pues significa oponerse al proyecto político de la burguesía financiera. Segundo, la condición de un programa que busque terminar con el neoliberalismo debe apuntar a sus nodos estratégicos que son los ya descritos. Tercero, un programa antineoliberal no puede y no debe sustituir un programa anticapitalista que apunte no solo a un nuevo Estado (de transición), sino a las relaciones sociales de producción y a la propiedad privada de los medios productivos.

Esto nos pone frente a lo que probablemente sea la mayor tarea del marxismo de hoy: la construcción de una teoría moderna del socialismo que incluya una explicación de las ineficiencias e injusticias del capitalismo junto a un proyecto teórico para corregir esas fallas en un socialismo factible (Roemer, 1989, p. 10). Este desafío no es solo teórico, sino también político y cobra especial relevancia a la hora de evaluar los gobiernos posneoliberales latinoamericanos que presentan evidentes signos de estancamiento. La necesidad de caracterizar el Estado neoliberal está dada por lo que parece ser su éxito: la despolitización y la aceptación, consciente o no, de que no existen alternativas de sociedad. De ahí que la teoría y el discurso político hayan abandonado la crítica al capitalismo para refugiarse en esta entidad a menudo difusa que sería el neoliberalismo, ya sea como ideología o gubernamentalidad. Sin embargo, esta alternativa, 
al carecer de una problematización del modo de producción, rápidamente llegó a su límite: sin un proyecto teórico y político de socialismo, los programas antineoliberales, centrados exclusivamente en la recuperación de derechos sociales, parecen destinados a terminar en un callejón sin salida. La posibilidad de salir de ahí está dada, como dice Roemer, al pensar una teoría factible de socialismo que apunte a las bases materiales del capitalismo — no solo del neoliberalismo - pero, a su vez, superando la noción estatista que caracterizó los regímenes socialistas del siglo Xx. Futuras discusiones sobre neoliberalismo deben abordar esta arista para dotar de contenido teórico a una táctica y a una estrategia política que deseen cuestionar el modo de producción capitalista.

\section{Referencias}

Althusser, L. (2004). La revolución teórica de Marx. México: Siglo XXI.

Althusser, L. (2008). Ideología y aparatos ideológicos del estado: Frend y Lacan. Buenos Aires: Nueva Visión.

Anderson, P. (2003). Neoliberalismo: un balance provisorio. En E. Sader \& P. Gentili (Eds.), La trama del neoliberalismo. Mercado, crisis y exclusión social (pp. 11-18). Buenos Aires: CLACSO.

Aricó, J. (2012). Nueve lecciones sobre economía y política en el marxismo. Buenos Aires: Fondo de Cultura Económica.

Arredondo, F. (2015). Los trabajadores honorarios como una arista de la modernización del Estado. Cuadernos de coyuntura, (9), 1-13.

Boron, A. (2004). Imperio \& imperialismo: Una lectura crítica de Michael Hardt y Antonio Negri. Buenos Aires: ClACsO.

Bourdieu, P. (1998). Neo-liberalism, the Utopia (Becoming a Reality) of Unlimited Exploitation. En Acts of resistance. Against the tyranny of the market (pp. 94-105). New York: New Press.

Buendía García, L., Mateo, J. P. \& Medialdea, B. (2013). ¿Alternativas al neoliberalismo en América Latina?: Las políticas económicas en Venezuela, Brasil, Uruguay, Bolivia y Ecuador. Madrid: Fondo de Cultura Económica.

Dahse, F. (1983). El poder de los grandes grupos económicos nacionales. Santiago: FLACSO. Recuperado de http:// flacsochile.org/biblioteca/pub/memoria/1983/001063.pdf 
Dávalos, P. (2008). Neoliberalismo político y Estado social de derecho. Recuperado de https://www.puce.edu.ec/documentos/NeoliberalismoyEstadosocialdederecho.pdf

Eagleton, T. (1991). Ideology: An introduction. London: Verso.

Engels, F. (1980). Discurso ante la tumba de Marx. En Obras escogidas (pp. 91-92). Moscú: Progreso.

Fazio, H. (2014). El mundo del $1 \%, 0.1 \%$ y $0.01 \%$. Chile: Universidad de Santiago de Chile.

Featherstone, M. (2007). The End of History: Utopian Realism and the Politics of Idiocy. Journal of Classical Sociology, 7(1), 109-126.

Fundación Nodo XXI. (2015). Avanzar en educación pública sin recursos adicionales: Análisis de las tendencias centrales del financiamiento estatal a la educación superior. Santiago: Grupo de Estudios de Educación, Fundación Nodo XXI. Recuperado de http:/ / www.fundacionemerge.cl/noticias/avanzar_en_educacion_superior_publica_sin_recursos_adicionales.pdf

Gárate, M. (2012). La revolución capitalista de Chile (1973-2003). Chile: Universidad Alberto Hurtado.

Garretón, M. A. (2013). Neoliberalismo corregido y progresismo limitado: Los gobiernos de la Concertación en Chile, 1990-2010. Santiago de Chile: Editorial ARCIS; CLACSO; El Desconcierto.

Ghersi, E. (2004). El mito del neoliberalismo. Revista Estudios Públicos, (95), 293-313.

Habermas, J. (1999). Problemas de legitimación en el capitalismo tardio. España: Cátedra.

Harvey, D. (2004). El nuevo imperialismo. Madrid: Akal.

Harvey, D. (2015). Breve historia del neoliberalismo. Buenos Aires: Akal.

Hayek, F. von. (1982). Los principios de un orden social liberal. Revista Estudios Públicos, (6), 179-202.

Laval, C. \& Dardot, P. (2013). La nueva razón del mundo: Ensayo sobre la sociedad neoliberal. Barcelona: Gedisa.

Lenin, V. I. (1960). El Estado y la revolución. La doctrina marxista del Estado y las tareas del proletariado en la revolución. En Obras escogidas (pp. 291-389). Moscú: Progreso.

Marx, C. (2006). El capital: Crítica de la economía política. México: Fondo de Cultura Económica.

Marx, K. (2013). Contribución a la crítica de la economía politica. México: Siglo XXI. 
Mayol, A. (2012). El derrumbe del modelo: La crisis de la economía de mercado en el Chile contemporáneo. Santiago: LOM.

Polanyi, K. (2015). La gran transformación: Los orígenes políticos y económicos de nuestro tiempo. México: Fondo de Cultura Económica.

Politzer, G. (1961). Principios elementales de filosofía. Buenos Aires: Hemisferio. Poulantzas, N. (1972). Poder político y clases sociales en el Estado capitalista. México: Siglo XXI.

Poulantzas, N. (2005). Estado, poder y socialismo. México: Siglo XXI.

Roemer, J. E. (Comp.). (1989). El marxismo: Una perspectiva analitica. México: Fondo de Cultura Económica.

Springer, S., Birch, K. y MacLeavy, J. (Eds.). (2016). The handbook of neoliberalism. New York: Routledge Taylor \& Francis Group.

Therborn, G. (2003). La crisis y el futuro del capitalismo. En E. Sader \& P. Gentili (Eds.), La trama del neoliberalismo. Mercado, crisis y exclusión social (pp. 19-25). Buenos Aires: ClACSO.

Varas Marchant, K. (2016). Radiografía del empleo público en Chile: derechos laborales de los funcionarios públicos. En Informe anual sobre derechos humanos en Chile 2016 (pp. 239-277). Chile: Universidad Diego Portales.

Vargas Hernández, J. G. (2011). Liberalismo, Neoliberalismo, Postneoliberalismo. Revista Mad, (17), 66-89. 